\title{
DESIGN OF DEVELOPABLE SURFACES AND THE APPLICATION OF THIN-WALLED DEVELOPABLE STRUCTURES
}

\section{A B S T R A C T}

This manuscript is an attempt to collect and systematize all cardinal scientific results of geomet-rical design of nondegenerate developable surfaces with a cuspidal edge. Information on the application of thin-walled developable structures and developable surfaces has also been pre-sented. Wide choices of design methods of developable surfaces provide not only necessary shapes and special properties but they also prove to be convenient to apply. This surface is actively applied for design of ship hulls, in agricultural machine building, in aircraft construction, in pipe design for making the diverse transitions, in road building, in cartography and in civil engineering. 


\section{INTRODUCTION}

Cylindrical, conical, torse surfaces, a plane and surfaces of polyhedrons are called surfaces of zero Gaussian curvature or developable surfaces. These surfaces can be developed on a plane without any lap fold or break. During this process, the lengths of the curves and the angles between two curves belonging to the developable surface remain unchanged. A torse surface is generated by the tangent lines of its edge of regression (cuspidal edge). Any spatial curve can be taken as an edge of regression and the tangent lines of this curve will generate the particular torse surface. The cuspidal edge of a cone is a point (vertex of the cone). A surface of principal normals and that of binormals of any spatial curve cannot be a torse surface. Above, strict mathematical definitions are presented but most of engineers use the term "torse surface" or "torse" very seldom and that is why we shall use the term "developable surface" meaning "torse surface".

A problem of analytical presentation of a surface in the space and on the drawing is one of the important problems coming into existence in the process of design, investigation and machining of technological surfaces.

Since Archimedes time till present, developable surfaces attract the attention of geometricians and engineers. The author archive contains 400 published scientific works devoted to torse surfaces and shells. But some modern works contain results derived by other people earlier. That is why the author begins his paper with brief description of results of geometrical investigations obtained before, supplements it with his own new materials and raises problems for modern investigators in conformity with computer aided design. Static strength analysis of shells with developable middle surfaces is presented in a review manuscript ${ }^{1}$.

\section{THEOREMS FOR DEVELOPABLE SURFACES}

Let us put down all theorems for developable surfaces without proofs but with the indication of the works where these proofs are presented.

1. Any surface of tangent lines is a developable surface.

2. Any developable surface is either a cylindrical or conic surface, or else a surface of tangent lines.

3. A developable surface is generated by tangent lines of its edge of regression.

4. Only a degenerated developable surface in the shape of a plane may be a minimum surface. 
5. Right circular cylinder and right circular cone are the only developable surfaces of revolution ${ }^{2}$.

6. The curvature of a cuspidal edge remains constant in its every point if in the process of bending of the developable surface the rectilinear generators remain the rectilinear generators.

7. Every single parametrical system of planes with the exception of a pencil of planes passing through any axis or parallel to each other has an envelope surface, which is a developable surface ${ }^{3}$.

8. Every point of a cuspidal edge of the surface of tangents is a limit of the point of intersection of three infinitely near tangent planes of the developable surface.

9. After bending of a developable surface on a plane all its geodesic lines become the straight lines.

10. A geodesic line can be drawn through every point on every developable surface in every direction ${ }^{4}$.

11. Two surfaces can be moved up by bending from one into another surface if Gaussian curvature of both surfaces has the same constant value ${ }^{5}$. Therefore, all surfaces with zero Gaussian curvature may be produced by bending a fragment of a plane. This assertion has been proved by Finikov ${ }^{6}$ in 1952, and later by Dobrescu ${ }^{7}$ in 1958.

12. The normals to a surface along principal lines of curvatures form the developable surface, a cuspidal edge of which generates the applicable principal center of curvatures ${ }^{8}$.

13. A developable surface in contrast to another ruled non-developable warped surfaces has two adjoining rectilinear generatrices which intersect each other, while rectilinear generatrices of ruled non-developable surface are skew lines 9 .

14. An analytical surface cannot be bent with conservation of some rigid curve if this curve is not asymptotical line (J.H. Jellett's theorem).

15. If two developable surfaces are touching each other along some line, then this line presents a common generatrix ${ }^{10}$.

16. The evolute $L$ is the cuspidal edge of a developable surface $S$ formed by normals of the evolvent $l^{11}$.

17. After bending of a rectifying surface of a line $L$ in the plane, this line $L$ becomes a straight line.

18. If at any point of a developable surface, one of the normal sections not registering with a principal direction has a singular point with curvature equal to zero then all normal sections of this point have zero curvatures ${ }^{12}$.

19. Ratio $(k / \kappa)_{C}=k / \kappa$ examined on a spatial geodesic line $C$ of a developable surface $F_{2}$ is equal to tangent of the angle of the $C$ curve with a rectilinear 
generatrix of the $F_{2}$ surface $^{13}$. Here $k$ is curvature and $\kappa$ is torsion of the geodesic line $C$ of a developable surface.

20. If all rectilinear generatrices of a torse surface of normals of any curve are to turn round in the appointed normal planes on a constant angle then a new surface of normals will be developable one too ${ }^{14}$.

21. The horizontal projections of rectilinear generatrices of a constant slope surface, a directrix curve of which is a curve of invariable slope to the $H$ plane, constitute the constant angles with tangent lines to the horizontal projection of the directrix curve ${ }^{15}$.

\section{THE METHODS OF CONSTRUCTING DEVELOPABLE SURFACES}

Let us examine the methods of design of developable surfaces using specific examples.

Constructing of torse surfaces with two given directing curves by Monge's method

If a tangent plane touches two curves

$$
r_{l}(\beta)=f_{1}(\beta) i+F_{l}(\beta) j+\beta k \text { and } r_{2}(\gamma)=f_{2}(\gamma) i+F_{2}(\gamma) j+\gamma k
$$

simultaneously then it is obvious that

$$
\left(r_{1}^{\prime}(\beta), r_{2}{ }^{\prime}(\gamma), r_{1}(\beta)-r_{2}(\gamma)\right)=0 \text {. }
$$

Let us take two directrices in the form of two parabolas of the $n$ and $m$-power:

$$
\begin{aligned}
& x=f_{1}(z)=0, y=F_{1}(z)=a z^{n}=a \beta^{n} \text { and } \\
& x=f_{2}(z)=l, y=F_{2}(z)=b z^{m}=a \gamma^{m}
\end{aligned}
$$

then condition (1) will give

$$
\gamma^{m-1}=\frac{a n}{b m} \beta^{n-1}
$$

After elimination of three parameters $\Phi, \Psi$, and $\beta$ from four algebraical equations

$$
\begin{aligned}
& z-\beta=\left[x-f_{1}(\beta)\right] \Phi(c)+\left[y-F_{1}(\beta)\right] \Psi(c), \\
& z-\gamma=\left[x-f_{2}(\gamma)\right] \Phi(c)+\left[y-F_{2}(\gamma)\right] \Psi(c), \\
& f_{1}^{\prime}(\beta) \Phi(c)+F_{1}(\beta) \Psi(c)=1, \\
& f_{2}{ }^{\prime}(\gamma) \Phi(c)+F_{1}(\gamma) \Psi(c)=1
\end{aligned}
$$

obtained by Monge ${ }^{16}$, it is possible to find the equation of the single-parametric system of the planes

$$
\text { (4) } \quad M(x, y, z, \beta)=(n-1)(l-x) \beta^{n}+n \beta^{n-1}(x y-z l)+\left(l y-b x \gamma^{m}\right) / a=0
$$

not forgetting that $\gamma=\gamma(\beta)$. 
Example. Having assumed $m=2, n=4$ one can obtain $\gamma=2 a \beta^{3} / b$ and

$$
M(x, y, z, \beta)=3 a b(l-x) \beta^{4}+4 a^{2} x \beta^{6}-4 a b l z \beta^{3}+b l y=0 .
$$

Solving three equations $M(x, y, z, \beta)=0, \partial M / \partial \beta=0$, and $\partial^{2} M / \partial \beta^{2}=0$ jointly one can obtain the equation of the cuspidal edge as

$$
x=\frac{b l}{b-6 a \beta^{2}}, \quad y=\frac{-2 a^{2} \beta^{6}}{b-6 a \beta^{2}}, \quad z=-\frac{4 a \beta^{3}}{b-6 a \beta^{2}}
$$

The equation of a developable surface in an implicit form is determined after the elimination $\beta$ from two equations $M(x, y, z, \beta)=0$ and $\partial M / \partial \beta=0$ but it is very difficult to do.

The developable surface with two given directrix curves in the form of two parabolas of the second and forth power and its cuspidal edge is shown in Figure 1.

The method of design of developable surfaces on two given plane curves is applied widely for graphical construction. If two plane given directrix curves are lying in parallel planes then rectilinear generators pass through two points one of which belongs to one directrix curve but the second point lies on the second directrix curve and the tangent lines of both directrix curves in these points are parallel (Fig. $2, a) .{ }^{17}$

If two given plane directrix curves are lying in perpendicular planes then rectilinear generators pass through two points one of which belongs to one directrix curve but the second point lies on the second directrix curve and the tangent lines of both directrix curves in these points are intersected on the line of intersection of the planes containing given curves ${ }^{18}$ (Fig. 2, b).

Additional information about Monge's method and several examples of design of developable surfaces with various given directrix curves can be found in ${ }^{19}$.

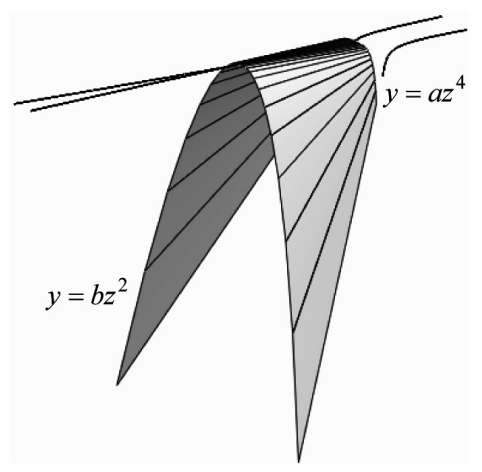

Figure 1 .

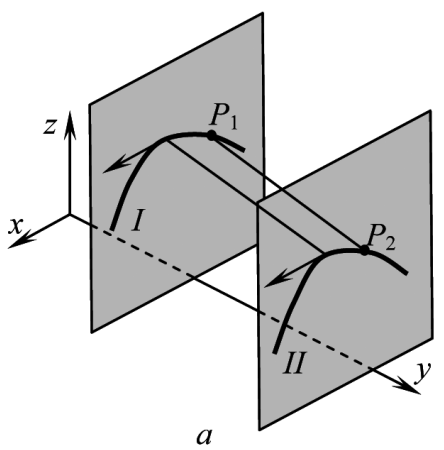

Figure 2 .

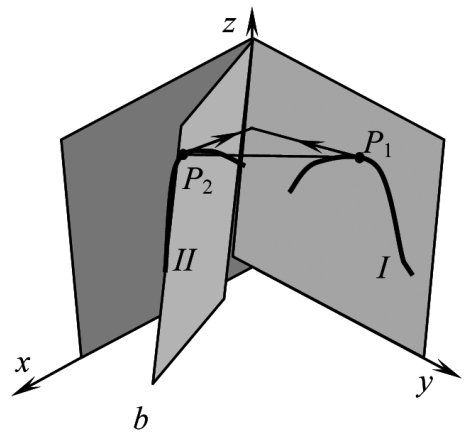


The equation of developable surface

obtained by Bhattacharya

If we have directrix curves $r_{1}=r_{1}(u)$ and $r_{2}=r_{2}(v)$, we may write the vector equation of a developable surface as

$$
r(u, \lambda)=r_{l}(u)+\lambda\left[r_{2}(v)-r_{I}(u)\right]
$$

where $0 \leq \lambda \leq 1, \lambda=|\overrightarrow{M P}| /|\overrightarrow{M N}|$ (Fig. 3).

Applying condition (1), Bhattacharya ${ }^{20}$ first obtained

$$
\begin{aligned}
& r_{2}(v)=r_{2}[v(u)]=R(u), \quad m(u)=R(u)-r_{1}(u) \text { and then } \\
& r(u, \lambda)=r_{1}(u)+\lambda m u
\end{aligned}
$$

Example. An illustration will make this clear. The ellipses

$$
x=0, y=b \sin u, z=a \cos u \text { and } x=l, y=b \sin v, z=d \cos v
$$

lie in parallel planes. Due to a condition (1) one can obtain $d \tan v=a \tan u$. Using the equations (7), it is easy to get parametrical equations of a torse surface with two ellipses (8) in the cross sections $x=0$ and $x=l$ :

$$
\begin{aligned}
& x=x(\lambda)=\lambda l, \quad y=y(\lambda, u)=b \operatorname{sinu}[1-\lambda+\lambda a / f(u)] \\
& z=z(\lambda, u)=\cos u\left[a-a \lambda+\lambda d^{2} / f(u)\right]
\end{aligned}
$$

where $f^{2}(u)=d^{2} \cos ^{2} u+a^{2} \sin ^{2} u, 0 \leq \lambda \leq 1$ (Fig. 4).

\section{Rijov's method of developable surfaces' design}

N.N. Rijov ${ }^{21}$ presented a new method for design of developable surfaces in 1972. He recommended representing a ruled surface with the help of equations of its generatrices

(9) $y=k x+l, z=m x+n$

where $k, l, m, n$ were functions only of one parameter. It was demonstrated that a surface given by rectilinear generatrices would be a developable surface if

(10) $\frac{d l}{d k}=\frac{d n}{d m}$, or $\frac{l^{\prime}}{k^{\prime}}=\frac{n^{\prime}}{m^{\prime}}$,

where $l^{\prime}, k^{\prime}, n^{\prime}, m^{\prime}$ are the derivatives of the functions with the one parameter. In this case, the parametrical equations of a cuspidal edge may be written as

$$
x=-\frac{d l}{d k}=-\frac{d n}{d m}, y=k x+l, z=m x+n
$$

A developable surface degenerates to a cone if by chance $-d l / d k=-d n / d m=$ const, or to a cylinder if $-d l / d k=-d n / d m=\infty$.

Example. Find the equations of a parabolic torse containing two parabolas

$$
x=\frac{(z-q)^{2}}{2 p_{2}}, y=0 \text { and } x=0, y=\frac{z^{2}}{2 p_{1}},
$$


lying in the perpendicular coordinate planes. From Eq. (1),

(13) $\gamma=\beta+q$,

where $\beta=z$ of a parabola lying in the coordinate plane $x O z$. The equation of a rectilinear generatrix passing through the points $P_{1}$ and $P_{2}$ (Fig. 2, b) can be written as

or

$$
\frac{x-f_{1}(\beta)}{-f_{1}(\beta)}=\frac{y}{F_{2}\{\gamma(\beta)\}}=\frac{z-\beta}{\gamma(\beta)-\beta} .
$$

$$
y=-\frac{F_{2}\{\gamma(\beta)\}}{f_{1}(\beta)} x+F_{2}\{\gamma(\beta)\}, \quad z=\frac{\beta-\gamma(\beta)}{f_{1}(\beta)} x+\gamma(\beta) .
$$

Substituting the expression (13) into Eqs (14), gives

$$
\begin{aligned}
& y=-\frac{(\beta+q)^{2} p_{2}}{(\beta-q)^{2} p_{1}} x+\frac{(\beta+q)^{2}}{2 p_{1}}=k(\beta) x+l(\beta), \\
& z=-\frac{2 p_{2} q}{(\beta-q)^{2}} x+(\beta+q)=m(\beta) x+n(\beta) .
\end{aligned}
$$

So, we determined the equations of a continued framework of rectilinear generatrices (9) of a parabolic torse (Fig. 5).

\section{Design of developable surface having only one given line of curvature $\alpha$ and one known line of curvature b}

The following theorem was proved by E.G. Utishev ${ }^{22}$ : If a straight line and a curve, orthogonal to this straight line and intersecting it, are given then a single parabolic surface exists and it has these lines as lines of principal curvatures.

Alimov ${ }^{23}$ constructed a developable surface with a given line of curvature $a$, which had the parametrical equations

$$
x=x(u), y=y(u), z=z(u) .
$$

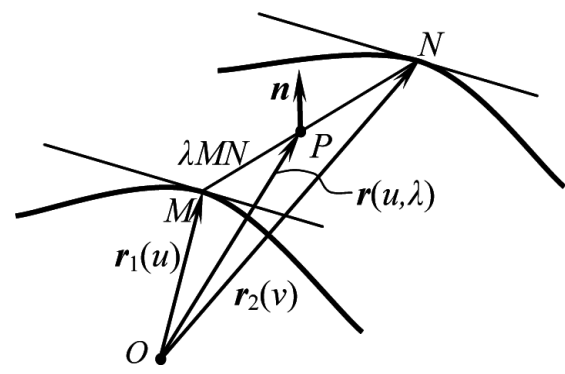

Figure 3 .

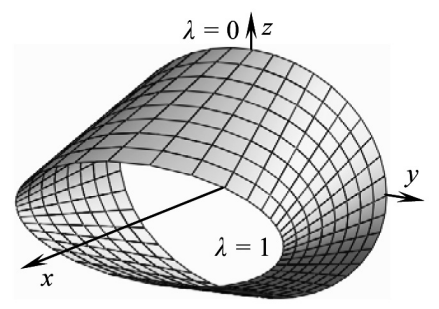

Figure 4 .

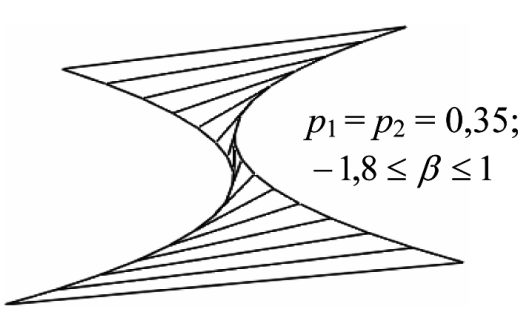

Figure 5 . 
First he has assumed a condition of intersection and a condition of orthogonality with the curve $a$ for system of straight lines (9), Fig. 6. Afterwards he used the condition (10) and derived the condition of developability

$$
\frac{d k}{d u}=\frac{\left(p^{\prime}+k q^{\prime}\right)(p k-q)}{1+p^{2}+q^{2}}, \text { where } p=x^{\prime} / z^{\prime}, q=y^{\prime} / z^{\prime} .
$$

Utishev $^{24}$ presented a design method for developable surfaces when the $a$ curve is given with the help of its tabular discrete meanings as a function of the arc length.

Example. Determine an equation of developable surface with a given line of curvature

$$
x=0, y=u, z=-a u^{2} .
$$

In this case, we have $\frac{d k}{d u}-\frac{1}{u\left(1+4 a^{2} u^{2}\right)} k=0$.

where $k=\frac{u c}{\sqrt{1+4 a^{2} u^{2}}}, c$ is a constant of integrating.

Write an equation of a tangent to the given parabola in the following form

$$
\frac{x-0}{0}=\frac{y-u}{1}=\frac{z+a u^{2}}{-2 a u}
$$

then an equation of a straight line perpendicular to this tangent is

or

$$
\frac{x-0}{l_{1}}=\frac{y-u}{2 a u n_{1}}=\frac{z+a u^{2}}{n_{1}},
$$

$$
\frac{2 a u n_{1}}{l_{1}} x+u=y, \quad \frac{n_{1}}{l_{1}} x-a u^{2}=z .
$$

Comparing the last equations with Eqs (9) we obtain

or

$$
k=\frac{u c}{\sqrt{1+4 a^{2} u^{2}}}, \quad l=u, \quad m=\frac{k}{2 a u}, \quad n=-a u^{2}
$$

$$
y=\frac{u c}{\sqrt{1+4 a^{2} u^{2}}} x+u, \quad z=\frac{c}{2 a \sqrt{1+4 a^{2} u^{2}}} x-a u^{2} .
$$

Parametric equations of the cuspidal edge of a torse (15) one can determine from formulas (11)

$$
\begin{aligned}
& x=-\left(1+4 a^{2} u^{2}\right)^{3 / 2} / c, \\
& y=-4 a^{2} u^{3}, \\
& z=-3 a u^{2}-1 /(2 a)
\end{aligned}
$$

The $c$ parameter is bound up with the $\varphi$ angle of a principle normal with a rectilinear torse generator passing through the parabola's peak by formula $c=2 \alpha \operatorname{ctg} \varphi$. A fragment of the developable surface shown in Fig. 7 is constructed for $c=2 \operatorname{\alpha ctg}(\pi / 6)$. 
Having known Eqs (16), it is easy to write the equations of the developable surface examined (Fig. 7)

$$
\begin{aligned}
& x=x(u, v)=-\frac{\left(4 a^{2} u^{2}+1\right)^{3 / 2}}{c}-\frac{2 a v}{\sqrt{4 a^{2}+c^{2}}}, \\
& y=y(u, v)=-4 a^{2} u^{3}-\frac{2 a c u v}{\sqrt{\left(4 a^{2}+c^{2}\right)\left(1+4 a^{2} u^{2}\right)}}, \\
& z=z(u, v)=-3 a u^{2}-\frac{1}{2 a}-\frac{c v}{\sqrt{\left(4 a^{2}+c^{2}\right)\left(1+4 a^{2} u^{2}\right)}} .
\end{aligned}
$$

\section{Analytical method of L.V. Gyachev}

L.V. Gyachev ${ }^{25}$ presented two analytical methods for the design of developable surfaces. He recommended representing a developable surface with the help of a given directrix and the equation of a curve of spherical representation of the designing surface. Gyachev has also described in detail the analytical method of design with the help of a given directrix and the equation of a spherical indicatrix of the tangent straight lines to geodesic lines of a designing developable surface. It is useful to read Gyachev's paper ${ }^{26}$ jointly with a work ${ }^{27}$.

\section{A geometrical modeling of developable surface with the help of known cuspidal edge}

This method is widely used in graphical design. Those who want to use analytical method may apply the equation of a developable surface in a vector form

$$
r=r(u, v)=\rho(v)+u l(v)
$$

where $\rho(v)$ is the radius-vector of a cuspidal edge, $\rho(v)=x(v) i+y(v) j+z(v) k$; $x=x(v), y=y(v), z=z(v)$ are the parametric coordinates of the cuspidal edge, $l(v)$ is a unit tangent vector, given in every point of the cuspidal edge by

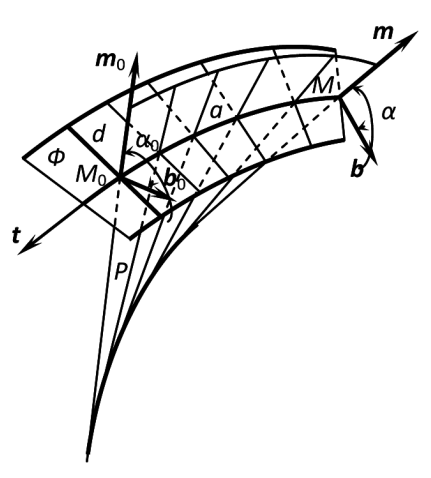

Figure 6.

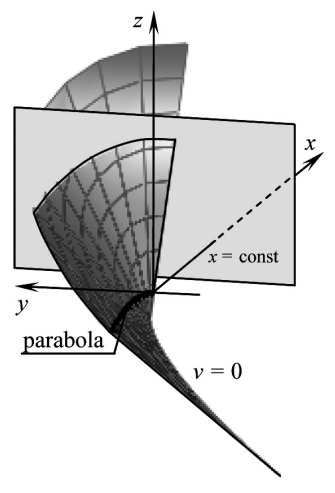

Figure 7 .

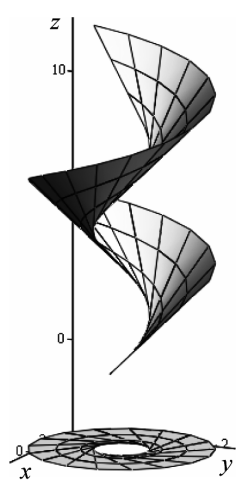

Figure 8 .

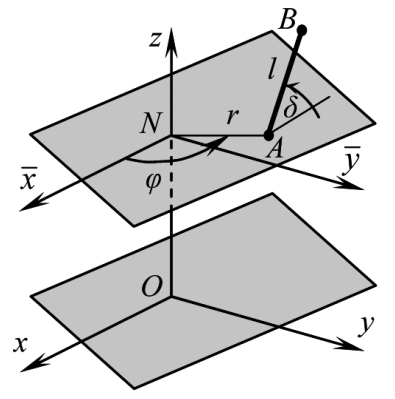

Figure 9 . 


$$
\boldsymbol{l}(v)=\frac{x^{\prime}(v) \boldsymbol{i}+y^{\prime}(v) \boldsymbol{j}+z^{\prime}(v) \boldsymbol{k}}{\sqrt{x^{\prime 2}(v)+y^{\prime 2}(v)+z^{\prime 2}(v)}} .
$$

Thus a developable surface with the curvilinear coordinates $u, v$ is obtained. The $u$ coordinates are the rectilinear generatrices of the surface and a curve $u=0$ is a cuspidal edge.

Example. Assume the parametric equations of a helix of constant slope in the form

$$
x=a \cos \frac{s}{\sqrt{a^{2}+b^{2}}}, y=a \sin \frac{s}{\sqrt{a^{2}+b^{2}}}, \quad z=\frac{b s}{\sqrt{a^{2}+b^{2}}},
$$

where $s$ is the arc length of the helix, $a=a_{0} \cos ^{2} \varphi ; b=a_{0} \sin \varphi \cos \varphi ; \varphi$ is the slanting angle of the rectilinear generators, $\tan \varphi=b / a, a_{0}$ is the radius of development of the helix (19) on a plane.

Substituting Eqs (19) into the expression (18) and after into Eq. (17), we shall get the parametric equations of open helicoid (Fig. 8)

$$
\begin{aligned}
& x=x(u, s)=a_{0} \cos ^{2} \varphi\left(\cos \frac{s}{m}-\frac{u}{m} \sin \frac{s}{m}\right), \\
& y=y(u, s)=a_{0} \cos ^{2} \varphi\left(\sin \frac{s}{m}+\frac{u}{m} \cos \frac{s}{m}\right), \\
& z(u, s)=(s+u) \sin \varphi, \text { where } m=\sqrt{a^{2}+b^{2}}=a_{0} \cos \varphi .
\end{aligned}
$$

\section{A kinematic method of rotation of a plane with a} straight line around a cone or around a cylinder

Assume, $\Sigma$ is a tangent plane to a cylinder with radius $r ; u$ is an angle of the $x$ axis with the normal to the plane $\Sigma ; t, v$ are the rectangular coordinates. Equations of a developable surface formed by the straight line lying in the rolling plane can be written as

$$
\begin{aligned}
& x(u, v)=r \cos u-t \sin u, y(u, v)=r \sin u+t \cos u, \\
& z=v, \text { but } t=c v+b-r u,
\end{aligned}
$$

where the lines $u=$ const and $v=$ const are the lines of principal curvature. This surface has the cuspidal edge $x(u)=r \cos u, y(u)=r \sin u, z(u)=(r u-b) / c$ in the shape of a helix on a circular cylinder with the $r$ radius. A surface (21) was named Monge's ruled surface.

The similar research may be performed if we take a tangent plane to a circular cone. This kinematic method is described adequately in the scholarly works of I.A. Skidan, for example, in ${ }^{28}$. 


\section{A kinematic method of A.M. Tevlin}

A new approach to kinematic methods of design of developable surfaces was presented by Tevlin ${ }^{29}$. He proposed to write the equations of ruled surfaces in the parametric form (Fig. 9)

$$
\varphi=\varphi(t), r=r(t), z=z(t), \delta=\delta(t)
$$

where $t$ is a time parameter, or in the form

$$
r=r(\varphi), z=z(\varphi), \delta=\delta(\varphi)
$$

The value of axial and radial spiral parameters can be presented as

$$
k_{z}=\frac{d z}{d \varphi}, \quad k_{r}=\frac{d r}{d \delta} .
$$

A kinematic method of A.M. Tevlin is used in graphical design of developable surfaces.

\section{Design of developable surface as lan envelope surface of a family of circular cones}

A.G. Varvaritsa ${ }^{30}$ demonstrated this method by the following example. Let us take a cone

$$
\operatorname{tg}^{2} \alpha\left[(x-a)^{2}+(y-b)^{2}\right]-z^{2}=0
$$

where $\alpha$ is the angle of a rectilinear generatrix with a plane $H ; a$ and $b$ are the coordinates of the cone vertex. Assume the equation of the trajectory of the cone vertex as $y=f(x)$ then $b=f(a)$, and the general equation of the cones will be as

$$
F(x, y, z, a)=\operatorname{tg}^{2} \alpha\left\{(x-a)^{2}+\left[y-f(a)^{2}\right]\right\}-z^{2}=0
$$

After differentiating on the $a$ parameter one can find

$$
\frac{\partial F}{\partial a}=f^{\prime}(a)[y-f(a)]+x-a=0
$$

An equation of the envelope surface $R(x, y, z)=0$ can be obtained after eliminating the $a$ parameter from the last two equations.

Developable surfaces resting on isolated space curve

Choosing a support contour, investigators have to take into account the two factors: 1) a support contour must have not more than two points of tangency with any plane and 2) a support contour is a smooth curve and the form of its plan is a convex isolated curve.

O. Giering ${ }^{31}$ proved that for given spatial curve, only two developable surfaces resting on it exist and every rectilinear generatrix of these surfaces intersects the given isolated curve in two points. An example of a geometrical constructing of a developable surface resting on an isolated space curve was presented by 
A.I. Volkov ${ }^{32}$. He has taken an isolated curve defined as a result of intersection of a cylinder and a hyperbolic paraboloid. An analogous problem was studied by L. Bourget ${ }^{33}$ who noted that this problem was bound up with manufacture of package in the shape of a cylindrical tube.

Motion of some plane curve into the section of developable surface

J.N. Gorbatovich ${ }^{34}$ presented a method of determination of parametrical equations of a cuspidal edge of the developable surface made from the given plane development. V.S. Obukhova and S.F. Pilipaka ${ }^{35}$ showed new solution of the problem in question. They used the condition of equality of arc lengths of two curves $L$ and $L^{*}$ and proved that not every plane curve $L$ may be transformed into the plane curve $L^{*}$ lying on a developable surface [18]. F. Myard ${ }^{36}$ showed how to superimpose an annulus on the open helicoid.

\section{APPLICATION OF THIN-WALLED SHELLS WITH DEVELOPABLE MIDDLE SURFACES}

It was noted at the beginning of this paper that shells in the shape of developable surfaces are the cheapest structures among many geometrical models. Wide choices of design methods of developable surfaces provide not only necessary shapes and special properties but they also prove to be convenient to apply. Developable surfaces are used not only in technical fields of human activity but even in the works of art. Developable sculptural forms of Ilhan Koman ${ }^{37}$ are of interest for the art+math community. Ilhan Koman used frequently mathematical concepts in creating his sculptures and discovered a wide variety of sculptural forms.

Application of the thin-walled developable structures in ship building

In ship building, developable surfaces are shaped using only rollers or presses ${ }^{38}$. Heat treatment is used for the correction of warps ${ }^{39}$.

Pavlenko ${ }^{40}$ proposed the theoretical bases of the construction of ship's hull of the simplified shape from pieces of developable surfaces in 1948 (Fig. 10). ${ }^{41}$ C.D. Barry calls this method as "Kilgore's Method". Ulhman Kilgore is a naval architect from the University of Michigan who described it in 1967. Developable surface are especially important to the home boat-builder because 
they are often working with sheet materials like plywood, steel or aluminum. The forces required to form sheet materials into developable surfaces are much less than for double curved surfaces ${ }^{42}$. Several examples of thin-walled developable structures for naval engineering systems were given in Geometry of ruled surfaces with cuspidal edge and linear theory of developable surfaces' analysis $^{43}$.

\section{Application of the thin-walled developable structures in aircraft construction}

Some works are devoted to the application of developable surfaces in aircraft manufacturing industry. A method of constructing of torse surfaces with the help of continuous movement of a straight on two directing given curves is the most convenient method. It is described in the part 3.1. The theoretical-andexperimental curves may be given in a table form or by other mathematical methods, for example, by the second order curves. A brochure ${ }^{44}$ is the earliest work devoted to the application of developable thin-walled structures in aircraft construction. A helicopter model and a model of f16 assembled out of heavy paper are presented by G. Elber ${ }^{45}$.

\section{Application of the thin-walled developable structures in agricultural mechanical engineering}

The application of developable surfaces in agricultural mechanical engineering was first offered by Goryachkin ${ }^{46}$ in 1927. Torse surfaces as geometrical models of ploughshares were examined and described in many scientific works ${ }^{47}$. Archimedes designed his screw for the transport of water. A surface of open helicoid (20) is widely used in agricultural mechanical engineering as a contrivance for transportation of dry, straw and semi-liquid measures.

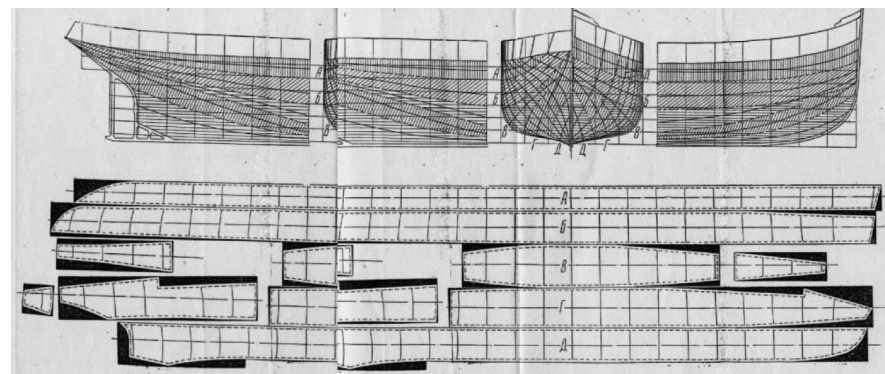

Figure 10 .

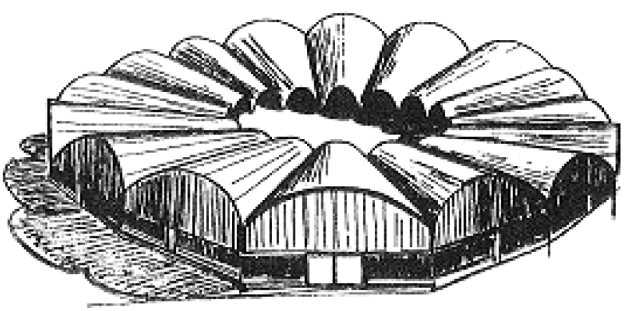

Figure 11 . 
Application of developable surfaces in road building and in design of anti-erosion bank

The geometrical properties of developable surface of constant slope can be used for the construction of slopes of embankments of main roads. ${ }^{48}$ An edge of permanent way was taken as a director curve.

The building of anti-erosion banks on slopes is one of the most effective means of fight against water erosion of soils. The well-known geometrical properties of developable surface of constant slope can be used for the approximation of topographic surfaces. ${ }^{49}$

Thibert B. et $a l^{50}$ has developed a program, DEVELOPABLE-MESH, that integrates diverse developability criteria and first builds a 3D mesh in cartography. This mesh is finally unfolded. This program has been tested on a natural example of the lateral evolution of a thrust system to a fold structure (Red Mountain area in the Venture basin). So, the DEVELOPABLE-MESH program builds near perfect developable folded surfaces.

\section{Developable surfaces in contemporary architecture}

The application of thin shells with developable middle surfaces can give positive effect in architecture due to their geometrical properties and the cheapest construction in practice. For instance, reinforced concrete shells in the shape of developable surfaces can be reinforced by plane or roll meshes and shutters can be made from rectilinear or sheet elements. ${ }^{51}$ (Fig. 11).

Georg Glaeser ${ }^{52}$ notes that in practice, developable surfaces are of value in avant-garde architecture, where smooth surfaces are requested and construction prices should not exceed certain limits. Several surfaces put together create new structures that are completely developable. Examples of the application of developable surfaces in modern architecture are presented in Developable surfaces in contemporary architecture..$^{53}$

The Center of Information Technologies in Architecture (CITA) (Sweden) working on a project The Research $\operatorname{devA}$ CITA continues to work out new effective ways of creation and design of complex surfaces on the basis of developable surfaces. 
Application of developable surfaces

in machine-building

Developable surfaces can be also geometrical models of technical structures from sheet materials. Such thin-walled shells are used for diverse conduits and pipelines. A helical conveyer in the form of a developable surface with a conic helical cuspidal edge was described in The using of a computer for design of the coal machine ${ }^{54}$. Methods of design of cylindrical gearing with teeth having a work surface in the shape of a developable surface are protected by a license 1523788 SSSR (Russia, 1988). Mechanical engineering is the main sphere of application of open helicoidal shells (Fig. 7). These shells are used in screw conveyers which consist of a trough, a rotating shaft on fixed bearings, and a long helix fastened on the shaft. The full length of a screw conveyer can reach $76 \mathrm{~m}$. A section of a helical surface maybe bent from a steel sheet with a thickness of 4-8 $\mathrm{mm}$. An open helicoid is used in blast-furnaces as a director surface in gas pipelines.

The information about initial stages of development of geometry of involute hob and gear teeth can be found in a paper of N.T.C. Peres. ${ }^{55}$

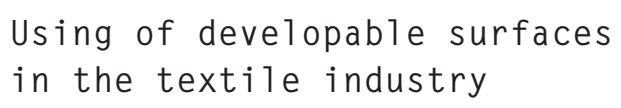

A.A. Bogushko ${ }^{56}$ worked out a computer program for construction of developments of some sections of surfaces in automatized process of design of clothes. The use of developable surfaces for making proper clothing is described in notes ${ }^{57}$ Additional information about the application of developable surfaces in the light and food industry can be found in [18].

\section{CONCLUSION AND FUTURE RESEARCH}

Developable surfaces are attractive due to their ability to form different configurations in a plane and in space. These surfaces can satisfy the various requirements of designers and geometricians who work in civil and industrial engineering, road building, aircraft construction, and shipbuilding. It was shown that developable surfaces had been investigated widely. Yet, many open problems remain. For instance, designers do not have a wide enough selection of specific developable surfaces. In monograph ${ }^{58}$, the author adduced only 10 developable surfaces obtained due to the known cuspidal edges (Part 3.6), 10 developable surfaces with two given plane director curves (Part 3.1), 
6 developable surfaces of constant slope, only one developable surface with a given line of curvature in the form of a second order parabola (Part 3.4), and two surfaces obtained with the help of a kinematic method presented in Part 3.7. The knowledge of theory of developable surfaces helps to study geometry of some complex surfaces. While developable surfaces have been widely used in engineering, design, and manufacture, they have been less popular in computer graphics, despite the fact that their isometric properties make them ideal primitives for texture mapping, some kinds of surface modeling, and computer animation..$^{59}$

Few papers are devoted to the parabolic bending of developable surfaces and to the realization of this bending in specific manufacture process (Theorems $9,11,14)$.

The number of published works devoted to the strength analysis of shells with the developable midsurfaces is much less than the number devoted to the geometry of these surfaces. This is bound up with the difficulties of defining developable surfaces in term of their curvature lines.

Thus, more works on geometrical and strength analysis are needed, both analytical and experimental. 
S.A. Pyasetskiy, "Some problems of differential geometry," Problems of modern mathematics and its teaching in university 108 (1974): 106-108.

M.Ya. Vigodski, Differential geometry (M.: GITTL, 1949), 512.

A.I. Kartashev, Surfaces of constant slope, PhD dissertation (Leningrad: LIIZT, 1954), 16.

G. Monge, Application of analysis to geometry ( M.: ONTI, 1936),699.

G.E. Pavlenko, Simplified shapes of ships (M.: MRF SSSR, 1948), 28. and V.S. Obukhova, "Universal model for automatized design of developable plough surfaces," Prikl. geom. i injenern. grafica 32 (1981): 13-17. and Christopher D. Barry, "Working with developable surfaces," Boatbuilder, Jan/Feb. (2001):1-8. and S.N. Krivoshapko, Geometry of ruled surfaces with cuspidal edge and linear theory of developable surfaces' analysis (Moscow: RUDN, 2009), 358.

G.E. Pavlenko, Simplified shapes of ships (M.: MRF SSSR, 1948), 28.

S.N. Krivoshapko, Geometry of ruled surfaces with cuspidal edge and linear theory of developable surfaces' analysis (Moscow: RUDN, 2009), 358.

B. Bhattacharya, "Theory of a new class of shells," Symposium on Industrialized Spatial and Shell Structures, Poland, (1973), 115-124.

N.N. Rijov, "An algorithm of deduction of developable surfaces' equations with consideration of the given condition," Prikl. geom. i injenern. Grafica (1972): 14, 3-8.

E.G. Utishev, “The design of developable surfaces by lines of curvatures," Prikladnaya geometriya (1967): 50-53.

R.U. Alimov, An algorithm of design and developing of developable surfaces for automation of construction of developments on a plane for pipelines, PhD dissertation (M.: MAI, 1984): 19.

E.G. Utishev, “Tabular description of developable surfaces' lines of curvatures," Trudi Taganrog. radioteh. in-ta (1976): 46, 68-70.

L.V. Gyachev, “Theory of a plough surface,” Trudi AChIMSH, 13 (1961): 318.

Ibid.

F. C. Park, Yu Junghyun and Chun Changmook, "Design of developable surfaces using optimal control," Journal of Mechanical Design, December 2002, Vol. 124, Iss. 4 (2002): 602-608.

I.A. Skidan, "Kinematic surfaces in hyperbolic coordinates," Prikl. geom. i injenern. Grafica (1972): 14, 78-82.

A.M. Tevlin, “A kinematical method of design and investigation of developable surfaces," Kinemat. metodi konstruirovaniya tehnich. Poverhnostey(1970): 213, 5-12.

A.G. Varvaritsa, “Approximation of topographical surface by a surface of constant slope," Prikl. geom. i injenern. Grafica (1976): 21, 39-42.

Oswald Giering, "Über die Sehnentorsen der Raumkurven," Proc. Cong. of Geometry, Thessaloniki, 1-6 June 1987, 27-45.

A.I. Volkov, "Geometry of a developable surface resting on an isolated space curve," Voprosi nachertat. geom. i eyo prilojenie (1963): 25-28.

L. Bourget, "Surfaces développables $\Sigma$ passant par une conurbe (C) tracée sur un cylinder de revolution $S$, les génératrices de $\Sigma$ S'appliquant sur celles de $S$ quand on développe $\Sigma$ sur $\mathrm{S}$, (C) restant fixe," Rev. math. spec. (1964-1965): 605-609.

J.N. Gorbatovich and Y.G. Kardashevskaya, "Construction of development of plough surface with taken into account internal geometry of the surface," Agricultural machines, 13 (1) (1976): 68-73. V.S. Obukhova and S.F. Pilipaka, "Rolling up of a plane fragment into the torse with the condition of movement of the fragment in the position of a given curve of the cross section of the torse," Prikl. geom. i injenern. Grafica (1987): 44, 23-26.

F. Myard, "Sur une génération des surfaces réglées développables dont l'helicoide," Arts et manuf. 225 (1972): 9-10.

Ilhan Koman and Franoise Ribeyrolles, On my approach to making nonfigurative static and kinetic sculpture, Leonardo (NY: Pergamon Press). 1-4.

Jiman Yang, Yunsok Ha and Kim Hyochul, "Production method of FRP boat using developable surface without a mould," Journal of the Society of Naval Architects of Korea, Vol. 42, Issue 5 (2008): 506-515. 
Julie Steel-Chalfant, Analysis and design of developable surfaces for shipbuilding: Master's thesis. (Massachusetts Inst. of Tech. Cambridge Dept. of Ocean Engineering, 1997).

G.E. Pavlenko, Simplified shapes of ships (M.: MRF SSSR, 1948), 28.

An analogous graphical method of design of developable surfaces containing two given lines is under consideration in the work of Christopher D. Barry, "Working with developable surfaces," Boatbuilder, Jan/Feb. (2001):1-8.

Ibid.

S.N. Krivoshapko, Geometry of ruled surfaces with cuspidal edge and linear theory of developable surfaces' analysis (Moscow: RUDN, 2009), 358.

D.M. Orlov, et al, On approximate substitution of non-developable surfaces of sheathing wing of a airplane by the developable surface (Kiev: KIAVU VVS, 1959): 15.

Elber Gershon,"Model fabrication using surface layout projection," CAD, Vol. 27,4 (1995): 283291.

V.P. Goryachkin, Theory of plough (M.: Promizdat, 1927): 200.

For example: V.S. Obukhova, "Universal model for automatized design of developable plough surfaces," Prikl. geom. i injenern. grafica 32 (1981): 13-17, S.N. Krivoshapko, Geometry of ruled surfaces with cuspidal edge and linear theory of developable surfaces' analysis (Moscow: RUDN, 2009), 358., L.V. Gyachev, “Theory of a plough surface," Trudi AChIMSH, 13 (1961): 318., J.N. Gorbatovich and Y.G. Kardashevskaya, "Construction of development of plough surface with taken into account internal geometry of the surface," Agricultural machines, 13 (1) (1976): 68-73. Two examples of the application of the developable surfaces of constant slope in railway construction are presented in A.I. Kartashev, Surfaces of constant slope, PhD dissertation (Leningrad: LIIZT, 1954), 16.

A.G. Varvaritsa, "Approximation of topographical surface by a surface of constant slope," Prikl. geom. i injenern. Grafica (1976): 21, 39-42.

Boris Thibert, Jean-Pierre Gratier and Jean-Marie Morvan, "A direct method for modeling and unfolding developable surfaces and its application to the Venture Basin (California)," Journal of Structural Geology, Vol, 27, Issue 2 (2005): 303-316.

Some sketches of buildings in the shape of developable shells are presented in S.N. Krivoshapko, Geometry of ruled surfaces with cuspidal edge and linear theory of developable surfaces' analysis (Moscow: RUDN, 2009), 358.

Georg Glaeser, "The beauty of developable surfaces," in Computational Aesthetics in Graphics. Visualization and Imaging: Abstracts (2007): 5.

Georg Glaeser and Gruber Franz, "Developable surfaces in contemporary architecture," Journal of Mathematics and the Arts, Vol. 1, Issue 1, (2007): 59-71.

I.A. Skidan and A.M. Skirda, "The using of a computer for design of the coal machine "USM2000"," Prikl. geom. i injenern. Grafica (1982): 34, 135-139.

N.T.C. Peres, "Geometry of involute helicoidal hob and gear teeth,” Austral. J. Appl. Sci., 5, № 4 (1954): 309-329.

A.A. Bogushko, "A design of developments of torse surfaces with the help of computers," Prikl. geom. i injenern. Grafica (1989): 47, 49-50.

Miori Ito and Haruki Imaoka, "A method of predicting sewn shapes and a possibility of sewing by the theory of developable surfaces," Journal of the Japan Research Association for Textile End-Uses, Vol. 48, No 1 (2007): 42-51.

S.N. Krivoshapko, Geometry of ruled surfaces with cuspidal edge and linear theory of developable surfaces' analysis (Moscow: RUDN, 2009), 358.

Sun Meng and Eugene Fiume, "A Technique for Constructing Developable Surfaces," Proceedings of Graphics Interface '96, (May. 1996): 176-185. 
Alimov, R. U. An algorithm of design and developing of developable surfaces for automation of construction of developments on a plane for pipelines, PhD dissertation (M.: MAI, 1984): 19.

Barry, Christopher D. "Working with developable surfaces," Boatbuilder, Jan/Feb. (2001):1-8.

Bhattacharya, B. "Theory of a new class of shells," Symposium on Industrialized Spatial and Shell Structures, Poland, (1973), 115-124.

Bogushko, A. A. "A design of developments of torse surfaces with the help of computers," Prikl. geom. i injenern. Grafica (1989): 47, 49-50.

Bourget, L. "Surfaces développables $\Sigma$ passant par une conurbe (C) tracée sur un cylinder de revolution $S$, les génératrices de $\Sigma$ S'appliquant sur celles de $S$ quand on développe $\Sigma$ sur S, (C) restant fixe," Rev. math. spec. (1964-1965): 605-609.

Deaux, R. "Géodésiques d'un hélicoide developable ou d'un cone revolution," Mathesis, 63, 9-10(1954): 363-365.

Dobrescu, A. "Asupra suprafetelor desfăsurabile,” Gaz. mat. - si. fiz., A10, 6 (1958): 331-333.

Finikov, S. P. A course of differential geometry.M.: GITTL, 1952.

Finikov, S. P. Differential geometry. M.: MGU, 1961.

Gershon, Elber. "Model fabrication using surface layout projection," CAD, Vol. 27, 4 (1995): 283-291.

Giering, Oswald "Über die Sehnentorsen der Raumkurven," Proc. Cong. of Geometry, Thessaloniki, 1-6 June 1987, 27-45.

Glaeser, Georg. "The beauty of developable surfaces," in Computational Aesthetics in Graphics. Visualization and Imaging: Abstracts (2007): 5.

Glaeser, Georg and Franz, Gruber. "Developable surfaces in contemporary architecture," Journal of Mathematics and the Arts, Vol. 1, Issue 1, (2007): 59-71.

Gorbatovich, J. N. and Kardashevskaya, Y. G. "Construction of development of plough surface with taken into account internal geometry of the surface," Agricultural machines, 13 (1) (1976): 68-73.

Goryachkin, V. P. Theory of plough. M.: Promizdat, 1927.

Gyachev, L. V. “Theory of a plough surface,” Trudi AChIMSH, 13 (1961): 318.

Hilbert, D. and Cohn-Vossen, S. Anschauliche geometrie. Berlin, 1932.

Ito, Miori and Imaoka, Haruki. "A method of predicting sewn shapes and a possibility of sewing by the theory of developable surfaces," Journal of the Japan Research Association for Textile End-Uses, Vol. 48, No 1 (2007): 42-51.

Kagan, V. F. Basis of the theory of surfaces in tensors.M.: OGIZ, 1947.

Kartashev, A. I. Surfaces of constant slope, PhD dissertation (Leningrad: LIIZT, 1954), 16.

Koman, Ilhan and Ribeyrolles, Franoise. On my approach to making nonfigurative static and kinetic sculpture, Leonardo. NY: Pergamon Press, 1-4.

Krivoshapko, S. N. Geometry of ruled surfaces with cuspidal edge and linear theory of developable surfaces'analysis. Moscow: RUDN, 2009.

Krivoshapko, S. N. "Static analysis of shells with developable middle surfaces.” Appl. Mech. Rev., 51, 12 (1)(1998): 731-746.

Meng, Sun and Fiume, Eugene. "A Technique for Constructing Developable Surfaces," Proceedings of Graphics Interface '96, (May. 1996): 176-185.

Monge, G. Application of analysis to geometry. M.: ONTI, 1936.

Myard, F. "Sur une génération des surfaces réglées développables dont l'helicoide," Arts et manuf. 225 (1972): 9-10.

Murray-Klamkin, S. "On ruled and developable surfaces of revolution," Math. Mag., 27, 4, (1954): 207-208.

Obukhova, V. S. and Pilipaka, S. F. "Rolling up of a plane fragment into the torse with the condition of movement of the fragment in the position of a given curve of the cross section of the torse," Prikl. geom. i injenern. Grafica (1987): 44, 23-26. 
Obukhova, V. S. "Universal model for automatized design of developable plough surfaces," Prikl. geom. i injenern. grafica 32 (1981): 13-17.

Orlov, D. M. et al, On approximate substitution of non-developable surfaces of sheathing wing of a airplane by the developable surface (Kiev: KIAVU VVS, 1959): 15.

Park, F. C., Junghyun, Yu and Changmook, Chun. "Design of developable surfaces using optimal control," Journal of Mechanical Design, December 2002, Vol. 124, Iss. 4 (2002): 602-608.

Pavlenko, G. E. Simplified shapes of ships. M.: MRF SSSR, 1948.

Peres, N. T. C. "Geometry of involute helicoidal hob and gear teeth," Austral. J. Appl. Sci., 5, № 4 (1954): 309-329.

Pogorelov, A. V. Geometrical theory of shell stability. M.: Nauka, 1966.

Pyasetskiy, S. A. "Some problems of differential geometry," Problems of modern mathematics and its teaching in university 108 (1974): 106-108.

Rijov, N. N. “An algorithm of deduction of developable surfaces' equations with consideration of the given condition," Prikl. geom. i injenern. Grafica (1972): 14, 3-8.

Skidan, I. A. "Kinematic surfaces in hyperbolic coordinates," Prikl. geom. i injenern. Grafica (1972): 14, 78-82.

Skidan, I. A. and Skirda, A. M. "The using of a computer for design of the coal machine "USM2000"," Prikl. geom. i injenern. Grafica (1982): 34, 135-139.

Steel-Chalfant, Julie. Analysis and design of developable surfaces for shipbuilding: Master's thesis. (Massachusetts Inst. of Tech. Cambridge Dept. of Ocean Engineering, 1997).

Tevlin, A. M. "A kinematical method of design and investigation of developable surfaces," Kinemat. metodi konstruirovaniya tehnich. Poverhnostey(1970): 213, 5-12.

Thibert, Boris, Gratier, Jean-Pierre and Morvan, Jean-Marie. "A direct method for modeling and unfolding developable surfaces and its application to the Venture Basin (California)," Journal of Structural Geology, Vol, 27, Issue 2 (2005): 303-316.

Utishev, E. G. Обвод развертывающихся поверхностей.Taganrog: Taganrog, 1983.

Utishev, E.G. "Tabular description of developable surfaces' lines of curvatures," Trudi Taganrog. radioteh. in-ta (1976): 46, 68-70.

Utishev, E. G. "The design of developable surfaces by lines of curvatures," Prikladnaya geometriya (1967): 50-53.

Varvaritsa, A. G. "Approximation of topographical surface by a surface of constant slope," Prikl. geom. i injenern. Grafica (1976): 21, 39-42.

Vigodski, M. Ya. Differential geometry. M.: GITTL, 1949.

Volkov, A. I. "Geometry of a developable surface resting on an isolated space curve," Voprosi nachertat. geom. i eyo prilojenie (1963): 25-28.

Yang, Jiman, Ha, Yunsok and Hyochul, Kim. "Production method of FRP boat using developable surface without a mould," Journal of the Society of Naval Architects of Korea, Vol. 42, Issue 5 (2008): 506-515. 


\section{PROJEKTOVANJE RAZVIJENIH POVRŠINA I PRIMENA TANKO-ZIDNIH RAZVIJENIH KONSTRUKCIJA}

\section{S.N. Krivoshapko, Svetlana Shambina}

Ovaj rukopis predstavlja pokušaj da se prikupe i sistematizuju svi najvažniji naučni rezultati geometrijskog dizajna nedegenerisanih razvijenih površina sa kuspidalnom ivicom. Isto tako je predstavljena $\mathrm{i}$ informacija o primeni tanko-zidnih razvijenih konstrukcija i razvijenih površina. Široki izbor metoda projektovanja razvijenih površina obezbeđuje ne samo neophodne oblike i posebne osobine već isto tako je pokazao da su pogodne za primenu. Ova površina se aktivno primenjuje za projektovanje brodskih trupova, u poljoprivrednoj mašinogradnji, u vazduhoplovnoj konstrukicji, u dizajnu cevi za pravljenje raznih prelaza, u izgradnji puteva, u kartografiji i u građevinrstvu.

KLJUČNE REČI: ŠOVRŠINE KOJE SE MOGU RAZVIJATI, MODELIRANJE POVRŠINA, DIFERENCIJALNA GEOMETRIJA, ARHITEKTURA, BRODSKI TRUP, ANTI-EROZIONI NASIPI, POJOPRIVREDNO MAŠINSTVO, GRAĐEVINARSTVO, IZGRADNJA PUTEVA, DIZAJN CEVI, KARTOGRAFIJA, OTVORENI HELIKOID 